\title{
Perception of Factors Affecting Studies and Well-Being: A Dental Student Perspective
}

\author{
Sarang Suresh Hotchandani ${ }^{1, \odot}$ Priya Rani Harjani \\ ${ }^{1}$ FCPS Resident, Operative Dentistry, Liaquat University of \\ Medical \& Health Sciences, Jamshoro, Pakistan \\ 2Department of Operative Dentistry, Bibi Aseefa Dental College, \\ Larkana, Pakistan \\ ${ }^{3}$ Oral \& Maxillofacial Surgery, Dow University of Health Sciences, \\ Karachi, Pakistan \\ ${ }^{4}$ Oral \& Maxillofacial Surgery, Jinnah Sindh Medical University, \\ Karachi, Pakistan
}

Eur Dent Res Biomater J 2020;1:14-19

\author{
Muhammad Ilyas Shaikh ${ }^{3}$ Safia Khatoon ${ }^{4}$
}

\begin{abstract}
Keywords

- stress factors

- academic

- dental students

- survey

Objective This study aimed to assess the perception of factors affecting studies and well-being among students of the Bibi Aseefa Dental College, Larkana, Sindh, Pakistan. Materials and Methods Students of the Bibi Aseefa Dental College of various professional years were asked to respond to an online-based survey (Google Forms), which was then evaluated by SPSS 16.0 (SPSS Inc.; Chicago Illinois, United States) using the analysis-of-variance test. The study sample consisted of stratified random sampling. Inclusion criteria included students from year 1 to year 4 of their undergraduate studies during the study period of June 2019 to August 2019. Descriptive statistics including frequency and distribution regarding gender, year of study, age, external factors (stress, sleep, health, hobbies, financial, friends, paid work, voluntary work), reasons for choosing dentistry, and how these factors affecting the study were created.

Results The results showed that 97 students chose Bachelor of Dental Study (BDS) as a career because they were not selected in Bachelor of Medicine and Bachelor of Surgery (MBBS). Overall, 52.41\% students agreed that external factors are affecting their studies, $46.8 \%$ stated that they were stressed due to studies in past 12 months, $48.4 \%$ students agreed that their disturbed sleep due to academic assignments is affecting their studies, $29.9 \%$ stated that their health disturbance affected their studies in the past 12 months, and $48.4 \%$ responded that their own hobbies and sports work were affecting their academic grades.

Conclusion This study revealed that extracurricular factors were a cause of stress among dental students. The main cause of stress among the student was confusion about the syllabus of their academic year, resulting in a lack of sleep during the examination year, and favoritism among teachers for the students.
\end{abstract}

\begin{abstract}
Address for correspondence Sarang Suresh Hotchandani, BDS, RDS, FCPS, Department of Operative Dentistry, Liaquat University of Medical \& Health Sciences, Jamshoro, Sindh 76090, Pakistan (e-mail: hotchandanisarang@gmail.com).
\end{abstract}

\section{Introduction}

While an energizing background for some, learning at a medical or dental college or university can be a difficult time, with expanding reports of stress among undergraduate students. ${ }^{1}$

Stress in the literature is defined as external demands (physical or mental) on an individual's physical and psychological well-being. ${ }^{2}$ Students associated with providing clinical care to people must gain enough expertise before taking professional tasks. The literature revealed that health care students during their studies or clinical training experience some emotional and physical distress, which impairs their undergraduate studies. ${ }^{3-5}$

There are certain factors that particularly during undergraduate studies affect dentistry students, with the key 
contributor being academic factors impacting the studies of dentistry students along with personal issues and stress. ${ }^{6}$ Academicians need to focus on personal, professional, and academic factors impacting the studies of undergraduates.

Occasional stress is desirable to forestall boredom and understimulation for studies; however, persistent stress results in the opposite effect on the mental and physical health of a student. It is therefore recommended to determine the detrimental effects of stress on dental students to prevent damage to their physical their mental health. Students perceive stress due to the tendency of achieving perfectionism and dealing with peer pressure.

There is little focus toward dental education in Pakistan with respect to their less defined curriculum, proper pattern of preclinical rotations, and lack of knowledge of prospects in dentistry profession. The reason of this study was to gather information from the students to make strong evidence for the modification of dental curriculum by higher authorities. Therefore, the aim of this study was to examine the factors causing stress among undergraduate dental students.

\section{Materials and Methods}

Institutional permission was obtained prior to commencement of the study. The study used a cross-sectional survey gathering information through online survey feedback form (Google Forms, Google Inc.) from students of the Bibi Aseefa Dental College, Larkana, Sindh, Pakistan. The choice of response was purely voluntarily.

The survey form was prepared after personal discussion with undergraduate students stating their personal, financial, and medical issues. The questions contained a 5-point scale, ranging from completely disagree to completely agree. The questionnaire was tested on nonmedical undergraduates to obtain the clarity and comprehensibility of students. If participants declined the answer of any questions in the questionnaire, it was interpreted as a missing value. Web site link to the questionnaire was sent to the respective college students through social media, personal references, and e-mails to the faculty of the respective institute to gather as much as response as possible. The survey form was available online and accepted answers from June 2019 to August 2019. The questionnaire obtained the data from students regarding demographic details, year of study, institute name, hobbies, and financial issues; some open-ended questions were added to obtain data about interests and support outside studies.

The study sample consisted of stratified random sampling. Inclusion criteria included students from year 1 to year 4 of their undergraduate studies during the study period of June 2019 to August 2019 inducted in the 4-year dentistry program in Bibi Aseefa Dental College. No exclusion criteria or any benefits for response were provided.

Data from Google forms were exported to a spreadsheet and entered using SPSS 16.0 (SPSS Inc.; Chicago Illinois, United States). Descriptive statistics including frequency and distribution regarding gender, year of study, age, external factors (stress, sleep, health, hobbies, financial, friends, paid work, voluntary work), reasons for choosing dentistry, and how these factors affecting the study were created. For the item level presentation, multiple responses were dichotomized between 1 and 0 (yes = 1 ; no = 0 ). The choices that were selected were numbered as 1 , and those that were not selected were given a value of 0 . Multiple response factors were used, and dichotomies were calculated for 1, which meant "yes" for the factor. For the purpose of presentation, 28 questions regarding stress were grouped into two categories, "factors causing stress to students" and "how these factors are affecting my studies"; multiple responses were analyzed, as shown in (-Fig. 1-3). Multiple responses were analyzed by using multiple-response command in SPSS. Cross-tabulation was performed to assess the distribution of gender with respect to the year of study.

\section{Results}

Our study was a descriptive survey conducted on a total of 200 dental students enrolled during the study period in the college, with 50 students per batch. Of 200 students, 124 completed the online survey, resulting in a response rate of $62 \%$ (-Table $\mathbf{1}$ ). The mean age of students was 22.70 years, with a standard deviation of 2.231 . There were $63.7 \%(n=79)$ females and $36.3 \%(n=45)$ males (-Table 2).

A total of 65 (52.41\%) students agreed that external factors are affecting their studies, whereas 26 (21\%) disagreed with this question and 33 (26.6\%) remained neutral; 58 (46.8\%) stated that they were stressed for their studies in the past 12 months, with most of them being females (63.7\%; $n=37$ ). The clinical students (years 3 and 4 ) faced stress more than students in their initial years of under graduation (-Table $\mathbf{3}$ ).

Regarding the choice of dentistry, students were asked to choose a minimum of three reasons for joining dentistry as a profession. Results that showed 97 (78.2\%) students chose BDS (Bachelor of Dental Study) as a career because they were not selected in Bachelor of Medicine and Bachelor of Surgery (MBBS), whereas 61 (49.1\%) chose dentistry because it is a respectable career along with MBBS in health care industry (-Fig. 2).

A total of 40 (32.3\%) students had paid employment to support their monthly bills and reported that their studies are disturbed due to work commitments. Regarding external factors (-Fig. 1 and - Table 4) affecting the studies, 48.4\% students agreed that their disturbed sleep due to academic assignments is affecting their studies; $29.9 \%$ stated that their health disturbance affected their studies in the past 12 months; $48.4 \%$ responded that their own hobbies and sports work affecting their academic grades. While $31.5 \%$ faced financial issues, resulting in decreased academic performance, $47.5 \%$ faced problems with their colleagues and friends, resulting in stress affecting their studies; $32.3 \%$ faced a decline in their academic performances due to committed paid work for their financial issues; $34 \%$ stated that extracurricular voluntary work in their institutes is affecting their academic studies; $49.2 \%$ agreed that there are other factors mentioned in the survey are affecting their studies. On enquiring with a brief description about which other factors 
Voluntary work commitments are affecting my studies.

Health issues affecting my studies over the past 12 ...

Financial worries are affecting my study.

Paid Work commitments are affecting my studies.

Issues with my friends are affecting my studies.

My Hobbies \& Sports activities affect my studies.

Lack of Sleep affecting my studies over the past 12.

Other than mentioned above are affecting my studies.

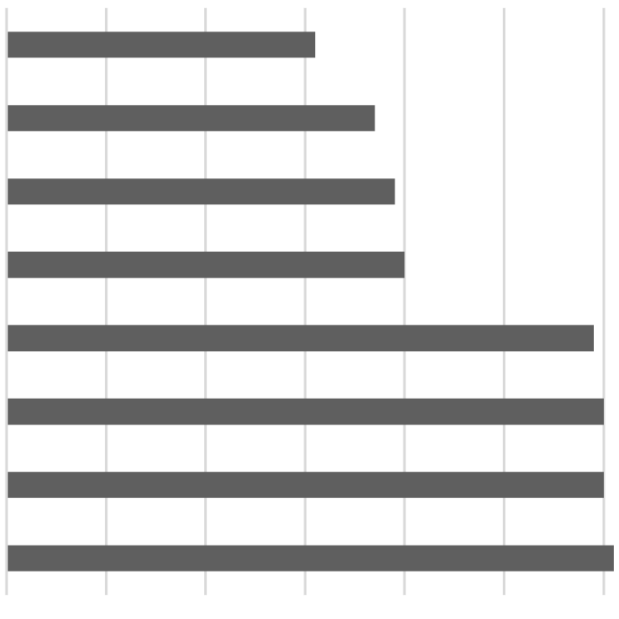

Factors Causing Stress to Students

Fig. 1 Factors causing stress among students.

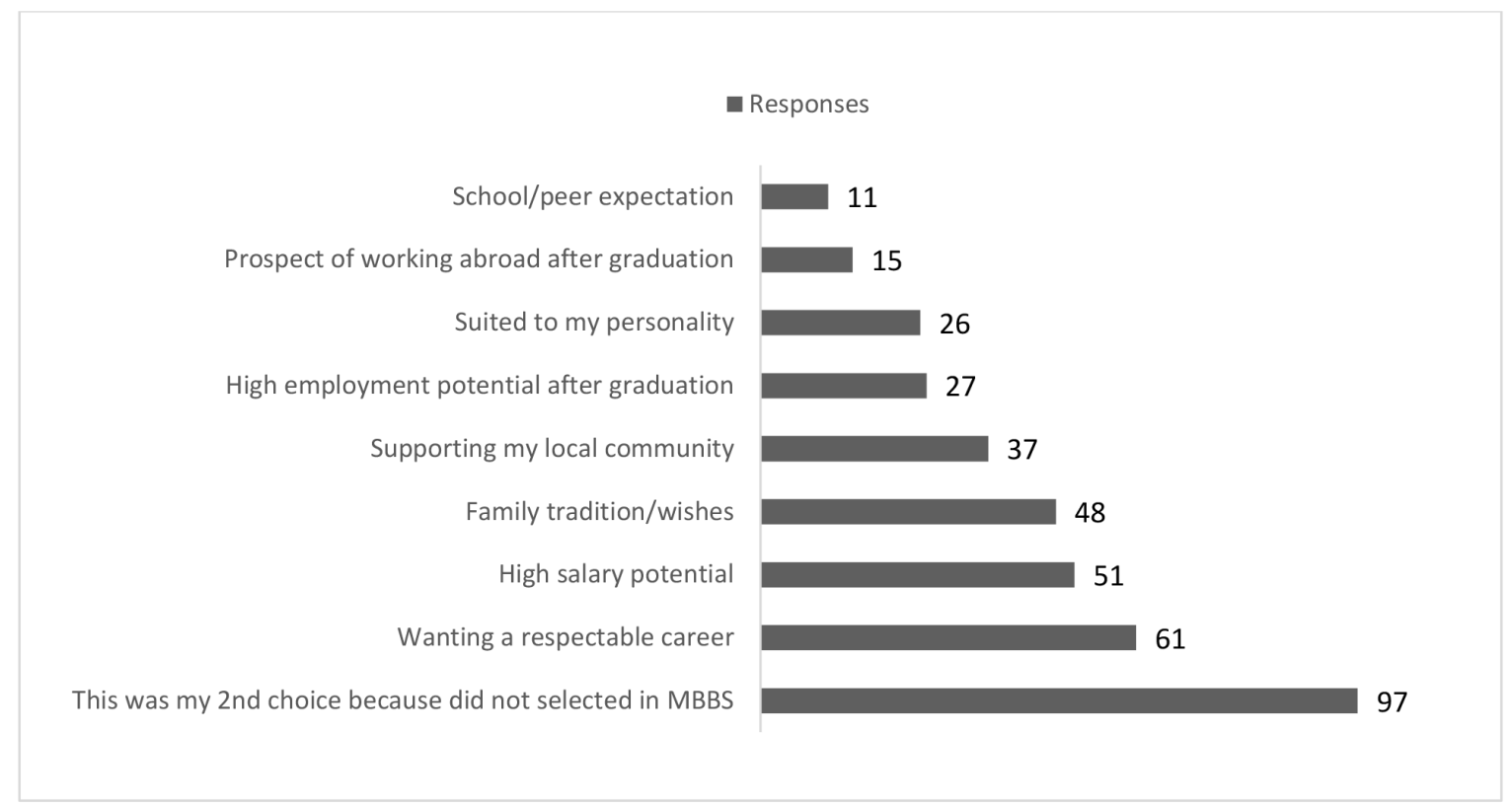

Fig. 2 Responses showing reasons for choosing dentistry as a profession.

affect their study, students described that environment of dental curriculum with much laboratory work even after the due time disturb them regarding our examination form acceptance and internal evaluation marks. No information of our course work till our examination disturbs our studies. Difficulty in learning dental procedures increases the tension among clinical students. How these factors affect their studies is shown in - Fig. 3.

Most of the students ( $n=98 ; 79 \%$ ) possessed hobbies outside their dental curriculum. Most of them included watching movies and playing sports and digital games. Very few of them reported reading informal books on self-development, philosophy, and politics.

\section{Discussion}

This article provides the baseline data about the perception of factors (academic and nonacademic) among students of a single dental institute in the interior of Sindh. This study has been conducted for the first time in Bibi Aseefa Dental 
Missing my work \& voluntary commitments

Missing classes \& academic commitments

Feeling alone / isolated

Lack of motivation

Emotional distress

Pressure of drop in academic performance

I feel fatigue all time

I feel depressed.

I feel stress and/or anxiety

Inability to focus/ forget things easily

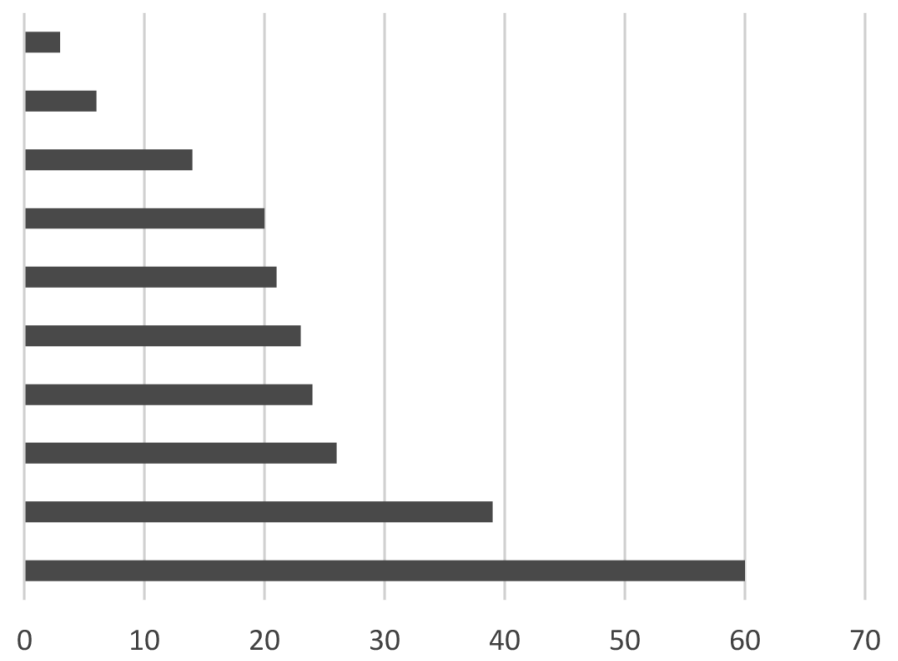

How These Factors are Affecting my Studies

Fig. 3 How these factors affect the studies of students.

Table 1 Distribution of responses with respect to the year of study

\begin{tabular}{|l|l|l|}
\hline Year of study & Frequency & Percentage \\
\hline 1 & 18 & 14.5 \\
\hline 2 & 34 & 27.4 \\
\hline 3 & 39 & 31.5 \\
\hline 4 & 33 & 26.6 \\
\hline
\end{tabular}

College, which is a public sector institute working under the public sector university Shaheed Mohtarma Benazir Bhutto Medical University, Larkana, Sindh, Pakistan. The dentistry program in this institute is a 4-year program. The first two years consist of basic medical and dental sciences, and clinical dentistry work is taken in the third and fourth years of the BDS program. This institute follows a yearly examination system with lecture-based and hands-on training

Table 2 Sample description by the year of study and gender

\begin{tabular}{|c|c|c|c|c|c|c|c|}
\hline Year of study & Frequency & Male & Female & $\begin{array}{l}\text { Response } \\
\text { rate }\end{array}$ & Mean & $\begin{array}{l}\text { Standard } \\
\text { deviation }\end{array}$ & Chi-square \\
\hline First & 18 & 4 & 14 & $36 \%$ & \multirow[t]{4}{*}{2.70} & \multirow[t]{4}{*}{1.020} & \multirow[t]{4}{*}{2.071} \\
\hline Second & 34 & 12 & 22 & $68 \%$ & & & \\
\hline Third & 39 & 16 & 23 & $78 \%$ & & & \\
\hline Fourth & 33 & 13 & 20 & $66 \%$ & & & \\
\hline
\end{tabular}

Table 3 Sample description by responses on external factors affecting student's studies

\begin{tabular}{|l|l|l|l|l|l|}
\hline \multirow{2}{*}{ Response } & \multicolumn{4}{|c|}{ Tear of study } \\
\cline { 2 - 7 } & First & Second & Third & Fourth \\
\hline Strongly agree & 5 & 8 & 8 & 12 & 33 \\
\hline Agree & 7 & 9 & 12 & 4 & 32 \\
\hline Neutral & 3 & 10 & 10 & 10 & 33 \\
\hline Disagree & 2 & 2 & 6 & 2 & 12 \\
\hline Strongly disagree & 1 & 5 & 3 & 5 & 14 \\
\hline Total & 18 & 34 & 39 & 33 & 124 \\
\hline
\end{tabular}


Table 4 External factors affecting the studies

\begin{tabular}{|l|l|l|l|l|l|}
\hline Factor & Strongly agree & Agree & Neutral & Disagree & Strongly disagree \\
\hline $\begin{array}{l}\text { Lack of sleep affecting my studies } \\
\text { over the past } 12 \text { mo }\end{array}$ & $17(13.7 \%)$ & $43(34.7)$ & $21(16.9 \%)$ & $31(25.0 \%)$ & $12(9.7 \%)$ \\
\hline $\begin{array}{l}\text { Health issues affecting my studies } \\
\text { over the past } 12 \text { mo }\end{array}$ & $12(9.7 \%)$ & $25(20.2 \%)$ & $31(25.0 \%)$ & $40(32.3 \%)$ & $16(12.9 \%)$ \\
\hline $\begin{array}{l}\text { My hobbies \& sports activities are } \\
\text { affecting my studies }\end{array}$ & $18(14.5 \%)$ & $42(33.9 \%)$ & $16(12.9 \%)$ & $28(22.6 \%)$ & $20(16.1 \%)$ \\
\hline $\begin{array}{l}\text { Financial worries are affecting my } \\
\text { study }\end{array}$ & $25(20.2 \%)$ & $14(11.3 \%)$ & $20(16.1 \%)$ & $51(41.1 \%)$ & $14(11.3 \%)$ \\
\hline $\begin{array}{l}\text { Issues with my friends are affecting } \\
\text { my studies }\end{array}$ & $22(17.7 \%)$ & $37(29.8 \%)$ & $15(12.1 \%)$ & $34(27.4 \%)$ & $16(12.9 \%)$ \\
\hline $\begin{array}{l}\text { Paid work commitments are affecting } \\
\text { my studies }\end{array}$ & $13(10.5 \%)$ & $27(21.8 \%)$ & $30(24.2 \%)$ & $40(32.3 \%)$ & $14(11.3 \%)$ \\
\hline $\begin{array}{l}\text { Voluntary work commitments are } \\
\text { affecting my studies }\end{array}$ & $16(12.9 \%)$ & $15(12.1 \%)$ & $44(35.5 \%)$ & $33(26.6 \%)$ & $16(12.9 \%)$ \\
\hline Other factors are affecting my studies & $17(13.7 \%)$ & $44(35.5 \%)$ & $39(31.5 \%)$ & $10(8.1 \%)$ & $14(11.3 \%)$ \\
\hline
\end{tabular}

based undergraduate program. Our results showed that $58(46.8 \%)$ stated that they were stressed for their studies in the past 12 months, with the most of them being females (63.7\%; $n=37) ; 40$ (32.3\%) students had paid employment to support their monthly bills and reported that their academics are disturbed to work commitments.

This study supports the literature ${ }^{7-9}$ on stress among dentistry graduates affecting their studies. Students in this study showed the student's relationship with teachers and their study environment is disturbing their mental status and causing anxiety and stress among them, resulting in low academic grades than they expect from themselves; this point is supporting the evidence from the finding by Hollinshead, ${ }^{10}$ who found that poor student-teacher relationship and academic pressure create fear among students. The swiftness of the study was not causing stress, but the confusion regarding the syllabus ${ }^{11,12}$ is one of the important factors of stress among students. ${ }^{13}$ In this study, students mentioned that a lack of information of curriculum of study during their period generates anxiety regarding the topics in their examination, which is in agreement with the study by Goldstein ${ }^{14}$ that showed that unpredictable feedback from teachers was one of the sources of stress among students of initial years. Stress among students usually results from some teacher's evaluative and influential role, which can generate favoritism and nepotism for some students and causing stress among others. ${ }^{15}$ This can be prevented by a supportive and flexible attitude of a teacher. As also indicated in the study by Hafeez et al, ${ }^{16}$ mentoring support from a tutor builds a sense of confidence and responsibility among students. Students in their clinical period were more affected by the clinical procedures than studies, as indicated in the study by Ullah, ${ }^{17}$ where clinical dental students reported stress due to excessive workload.

Gender differences in this study showed that females were more stressed than their colleagues. This is because majority of students in medical and dental institutes of Sindh are females. And as a notion is present in developing societies such as Sindh, female dental students are discriminated against based on gender differences and are taken back from pursuing further studies or career in dentistry in areas like Sindh.

Financial issues are commonly reported as a source of stress among students, as our study results show that 31.5\% students have financial issues affecting their academic records. These findings are consistent with studies ${ }^{18,19}$ that show that student debt has a negative effect on academic performance.

Choice of admission against their first choice of MBBS is shown to be one of the causes of decrease in their academic performance and lack of interest in their selected subject.

Management of stress during dental studies has been reported to be encouraging ${ }^{20}$ using pass-fail grading system ${ }^{21}$ such as those used by the College of Physicians and Surgeons of Pakistan and other educational institutes, feedback, and teaching strategies.

We should be more focused on the changing in the curriculum of BDS along with introducing the grading system like other foreign undergraduate institutes.

\section{Conclusion}

This study found that missing classes and academic factors result in stress among dental students. Sixty-five (52.41\%) students showed that external factors affected their studies. The clinical students (years 3 and 4) faced relatively more stress than students in their initial years of under graduation. Ninety-seven (78.2\%) students chose BDS as a career because they were not selected in MBBS. The main cause of stress among the student was confusion about the syllabus of their academic year, resulting in a lack of sleep during the examination year, and favoritism among teachers for the students. It was observed females were more stressed than males due to the fear of not being allowed to pursue further studies in dentistry. Financial issues also played a role, which could be a result of lack of scholarships to dentistry students, which is 
common in the society like that of Pakistan. There is a need for organized academic calendar for the curriculum of dentistry students in Pakistan, with defining goals to be achieved during their professional year to avoid the confusion at the time of annual examinations.

\section{Conflict of Interest}

None declared.

\section{References}

1 Alzahem AM, van der Molen HT, Alaujan AH, Schmidt HG, Zamakhshary MH. Stress amongst dental students: a systematic review. Eur J Dent Educ 2011;15(1):8-18

2 Atkinson JM, Millar K, Kay EJ, Blinkhorn AS. Stress in dental practice. Dent Update 1991;18(2):60-64

3 Association of American Medical Colleges, Liaison Committee on Medical Education, Functions and structure of a medical school: standards for accreditation of medical education programs leading to the MD degree. Available at: https:// med.virginia.edu/ume-curriculum/wp-content/uploads/ sites/216/2016/07/2017-18_Functions-and-Structure 2016-03-24.pdf. Accessed April 16, 2020

4 Anderson M, Cohen J, Hallock J, Kassebaum D, Turnbull J, Whitcomb M, Report I Learning Objectives for Medical Student Education: Guidelines for Medical Schools. Washington, DC: Association of American Medical Colleges; 1998

5 AlFaris EA, Naeem N, Irfan F, Qureshi R, van der Vleuten C. Student centered curricular elements are associated with a healthier educational environment and lower depressive symptoms in medical students. BMC Med Educ 2014;14(1):192

6 Elani HW, Allison PJ, Kumar RA, Mancini L, Lambrou A, Bedos C. A systematic review of stress in dental students. J Dent Educ 2014;78(2):226-242

7 Thornton LJ, Stuart-Buttle C, Wyszynski TC, Wilson ER. Physical and psychosocial stress exposures in US dental schools: the need for expanded ergonomics training. Appl Ergon 2004;35(2):153-157
8 Grandy TG, Westerman GH, Lupo JV, Combs CG. Stress symptoms among third-year dental students. J Dent Educ 1988;52(5):245-249

9 Anders P, Tedesco L, Davis E, Brewer J. Educational environment, perceived stress, and symptoms of distress among dental students at three schools. J Dent Educ 1985;49(1):40

10 Hollinshead BS, Survey of Dentistry. Washington, DC: American Council on Education;1962:338-345

11 Sofola OO, Jeboda SO. Perceived sources of stress in Nigerian dental students. Eur J Dent Educ 2006;10(1):20-23

12 Ishaque MY, Farid H, Yasmeen S. Perceived causes of stress among dental undergraduates at army medical college, Rawalpindi. Dent J 2015;35(1):7-9

13 Dahlin M, Joneborg N, Runeson B. Stress and depression among medical students: a cross-sectional study. Med Educ 2005;39(6):594-604

14 Goldstein MB. Sources of stress and interpersonal support among first-year dental students. J Dent Educ 1979;43(12): 625-629

15 Garbee WH Jr, Zucker SB, Selby GR. Perceived sources of stress among dental students. J Am Dent Assoc 1980;100(6):853-857

16 Hafeez K, Wahaj A, Zafar MS. Evolving medical and dental education system in Pakistan. Pak Armed Forces Med 2015;65(4):564-567

17 Ullah R, Siddiqui F, Zafar MS, Iqbal K. Bullying experiences of dental interns working at four dental institutions of a developing country: a cross-sectional study. Work 2018;61(1):91-100

18 Ross S, Cleland J, Macleod MJ. Stress, debt and undergraduate medical student performance. Med Educ 2006;40(6):584-589

19 Considine G, Zappalà G. The influence of social and economic disadvantage in the academic performance of school students in Australia. J Sociol (Melb) 2002;38(2):129-148

20 El-Gilany AH, Amr M, Hammad S. Perceived stress among male medical students in Egypt and Saudi Arabia: effect of sociodemographic factors. Ann Saudi Med 2008;28(6):442-448

21 Rohe DE, Barrier PA, Clark MM, Cook DA, Vickers KS, Decker PA The benefits of pass-fail grading on stress, mood, and group cohesion in medical students. In Mayo Clinic Proceedings; Mayo Clin Proc 2006;81(11):1443-1448 